\title{
Sentimentos vivenciados por puérperas na realização do primeiro banho do recém-nascido no alojamento conjunto
} Feelings experienced by postpartum women in achieving the first bath of the newborn in rooming

\author{
Clarissa Morganna Santos Silva* \\ Janmilli da Costa Dantas* \\ Francisca Marta de Lima Costa Souza* \\ Richardson Augusto Rosendo da Silva* \\ Thais Rosental Gabriel Lopes* \\ Jovanka Bittencourt Leite de Carvalho*
}

\begin{abstract}
Resumo
O banho do recém-nascido propicia os primeiros cuidados dispensados pela mãe, além de trocas e ajustes interacionais entre eles, em busca da promoção e observação geral das condições físicas e motoras do bebê. O estudo objetiva investigar os sentimentos de puérperas na realização do primeiro banho de aspersão do recém-nascido no alojamento conjunto. Trata-se de um estudo descritivo com abordagem qualitativa realizado em uma Maternidade Escola no Nordeste do Brasil em 2013, no período de agosto a setembro de 2013 após aprovação do Comitê de Ética e Pesquisa sob o parecer n 14079113.0.0000.5568. Assim, após a análise das entrevistas com 27 puérperas, identificaram-se duas categorias referentes ao banho de aspersão com o recém-nascido, relacionados aos sentimentos maternos na realização do mesmo, tais seja, sentimento de felicidade e sentimento de medo. Conclui-se que os primeiros cuidados dispensados aos recém-nascidos pelas puérperas por meio do banho de aspersão permearam sentimentos antagônicos de felicidade e medo. A ligação entre o binômio é demonstrada por meio da alegria de estar cuidando do seu bebê durante o banho diário, bem como pelo receio de ter em mãos um ser ainda pequenino e frágil dotado de cuidados especiais.
\end{abstract}

Palavras-Chave: Alojamento Conjunto. Período Pós-Parto. Cuidado da Criança. Recém-Nascido. Enfermagem.

\begin{abstract}
The bath of a newborn child generates the first care taken by the mother. Furthermore, it provides a series of exchanges and interactional adjustments between the mother and the child, general observation of physical and motor conditions. The study objective to investigate the feelings of mothers in achieving the first spray bath of the newborn in the rooming. This is a descriptive study with qualitative approach carried out in a maternity hospital in northeastern Brazil in 2013. The study was approved by the Research Ethics Committee under report number 14079113.0.0000.5568.It was found after analysis of 27 interviewed mothers, two categories related to the spray bath of the newborn. The feelings of happiness and fear. It follows that the first care given to newborns by mothers through the spray bath permeated antagonistic feelings of happiness and fear. The connection between the binomial is demonstrated by the joy of being taking care of her baby during the daily bath, as well as by the fear of having at hand a being still tiny and fragile given special care.
\end{abstract}

Keywords: Rooming-in Care. Postpartum Period. Child Care. Infant, Newborn, Nursing.

DOI: $10.15343 / 0104-7809.20153903279286$

* Faculdade de Ciências da Saúde do Trairi (FACISA/UFRN) - Natal, RN - Brasil

Os autores declaram não haver conflitos de interesse. 


\section{INTRODUÇÃO}

O nascimento de um filho desperta diversos sentimentos na mãe. Ao exercer a maternidade é comum à mulher, demonstrar desconhecimento, falta de habilidade e defrontar-se com muitas tarefas para o bem-estar do recém-nascido.

Diante desta situação, torna-se difícil para as mulheres se sentirem realmente mães, considerando a dificuldade de adaptar-se as demandas que a maternidade exige e o pouco estímulo da família, de colocar em prática a nova rotina ${ }^{1}$.

Os cuidados com a criança iniciam-se no alojamento conjunto, um ambiente hospitalar considerado um espaço que visa a permanência do recém-nascido saudável, logo após o nascimento, com a mãe até a alta hospitalar. Este sistema possibilita a prestação de todos os cuidados assistenciais, bem como a orientação à mãe sobre a saúde de binômio (mãe e filho) ${ }^{2}$.

No alojamento conjunto, o enfermeiro realiza cuidados com o recém-nascido e a família. Dentre as diversas atribuições deste profissional está a educação em saúde, com vistas na orientação dos cuidados básicos da criança nos primeiros dias de vida como: banho, higiene, limpeza do coto umbilical, massagem de conforto, amamentação e possíveis sinais de complicação. Porém, para os pais a maior fragilidade dos cuidados orientados está relacionada ao banho do recém-nascido nos primeiros dias de vida. Dessa forma, a equipe de enfermagem deve envolver os pais durante este cuidado, fortalecendo, assim, os laços afetivos de ambos, sabendo que é imprescindível o conhecimento acerca do banho do neonato. ${ }^{3,4,5}$

No âmbito dos cuidados de higiene ao recém-nascido, além da higiene corporal, o banho proporciona à observação geral das condições físicas e motoras e promoção do conforto a socialização da criança com os pais e família. ${ }^{6}$

A técnica do banho deve ser demonstrada individualmente para as puérperas, no primeiro dia pós-parto, com o recém-nascido, e durante a demonstração as mães ficam como observadoras, para que a próxima higiene seja realizada pela genetriz sob a avaliação dos profissionais de enfermagem. ${ }^{7,8}$
O interesse pela temática surgiu durante a prática dos pesquisadores do presente estudo na realização de ações educativas no setor de alojamento conjunto de uma maternidade. Conforme as colocações sobre os cuidados iniciais que permeiam o banho do recém-nascido no alojamento conjunto, questionou-se: quais os sentimentos vivenciados pelas puérperas durante a realização do primeiro banho do recém-nascido no alojamento conjunto?

Assim, o estudo em apreço objetivou investigar os sentimentos das puérperas na realização do primeiro banho de aspersão do recém-nascido, no alojamento conjunto.

Neste sentido, o estudo é relevante, pois pretendeu contribuir com a prática dos profissionais de enfermagem no apoio à puérpera e família na realização do banho do neonato, na melhoria da assistência, proporcionando atendimento humanizado e integral.

\section{MATERIAL E MÉTODO}

Trata-se de uma pesquisa do tipo descritiva, com abordagem qualitativa, desenvolvida no Hospital Universitário Ana Bezerra (HUAB), no município de Santa Cruz, situado no interior do Estado do Rio grande do Norte, Nordeste do Brasil, no período de agosto e setembro de 2013. Este hospital é gerenciado pela Empresa Brasileira de Serviços Hospitalares (EBSERH), tem vinculação com Sistema Único de Saúde e é referência em parto humanizado para a região do Trairi.

A composição da amostra da pesquisa ancorou-se em premissas da tradição qualitativa, na qual não se confere relevância à representatividade estatística da amostra, no sentido de visar à generalização dos achados, mas ao acúmulo subjetivo ante o objeto a desvelar, correspondendo ao que se designa como amostra teórica. ${ }^{9}$

Dessa forma, a amostra foi dimensionada a ponto de permitir a compreensão, em profundidade, da produção subjetiva emergente na relação com os atores investigados. Com base nesses critérios da amostragem qualitativa, os informantes deste estudo foram 27 puérperas que tinham realizado o primeiro banho no seu bebê naquele hospital. 
Como critérios de inclusão, elencou-se puérperas que residiam em Santa Cruz, primíparas, acima de 19 anos de idade, que tinham realizado o primeiro banho no seu filho no alojamento conjunto. Dessa forma, excluíram-se do estudo as mães que ainda não tinham realizado o banho no seu filho, multíparas e que não concordaram em participar da pesquisa.

A coleta dos dados aconteceu no período de agosto a setembro de 2013. O contato inicial com as puérperas ocorreu no alojamento conjunto no momento em que elas haviam concluído o primeiro banho do recém-nascido. Nesta ocasião, explicou-se o objetivo do estudo garantindo o anonimato das mães envolvidas na pesquisa. Todas as entrevistas foram realizadas pelos autores do presente estudo em uma sala reserva dentro do hospital, longe de interrupções e visando manter o conforto e a privacidade das entrevistas.

Após aprovação do comitê de ética da Faculdade de Ciências da Saúde do Trairi, com o número do aparecer 352.848, teve inicio a pesquisa no HUAB. O objetivo do estudo foi explicado às participantes e convidadas a assinarem o Termo de Consentimento Livre e Esclarecido (TCLE) e o de Autorização para gravação de voz.

Utilizou-se como instrumento de pesquisa um roteiro para a entrevista semi-estruturada, com o propósito de caracterizar as entrevistadas quanto aos dados sócio-demográfico e investigar o sentimento das puérperas na realização do banho de aspersão do recém-nascido, no alojamento conjunto.

A coleta de dados aconteceu mediante aceitação da puérpera em participar da pesquisa, no momento em que se encontravam no ambiente do alojamento conjunto, a espera de completar às 48 horas de vida do neonato para ter alta hospitalar, caso o binômio estivessem bem. Na medida em que eram abordadas pelo entrevistador, as mães respondiam a entrevista. Os depoimentos foram gravados e transcritos na íntegra, com aquiescência das entrevistadas.

Os dados foram analisados por meio da análise conteúdo, composta por três etapas. A primeira consiste na pré-análise que busca a organização das entrevistas, através de leitura criteriosa; a segunda etapa explora o material em que os dados são codificados; por fim, a fase de interpretação dos resultados de maneira que sejam significativos e válidos. Para obtenção das categorias, utilizou-se a análise temática. Tal método constituiu-se como uma técnica de pesquisa social, sugerida para a realização de descrição das informações dos sujeitos, tendo como objetivo a interpretação das falas, de forma sistemática e objetiva. ${ }^{10}$

O presente estudo foi aprovado pelo Comitê de Ética em Pesquisa da Faculdade de Ciências da Saúde do Trairi (CEP/FACISA) da Universidade Federal do Rio Grande do Norte, Brasil, sob o parecer favorável $n^{\circ} 352.848$. Os aspectos éticos e legais que embasam esse estudo estão de acordo com as Diretrizes e Normas Regulamentadoras de Pesquisas da Resolução 466 de 23 de dezembro de 2013 do Conselho Nacional de Saúde. ${ }^{11}$

Para garantir o sigilo dos sujeitos, as falas dos mesmos foram identificadas nos resultados e discussão pela letra "P" e por número de 1 a 27 .

\section{RESULTADOS}

Relativo aos dados sócios demográficos das 27 puérperas entrevistadas, observou-se que a idade dessas variou de 18 a 39 anos, predominando a faixa etária de 18 a 25 anos. A maioria informou que sua renda familiar era de um salário mínimo e afirmou ter o ensino fundamental incompleto. No tocante às ocupações trabalhistas, evidenciou-se prevalência de atividades domésticas. Concernente à realização do pré-natal, a maior parte das genetrizes participaram em média de 5 a 10 consultas. Destaca-se que durantes estas consultas não foram orientadas quanto o banho do recém-nascido.

Quanto ao banho do neonato realizado no alojamento conjunto, 23 mães afirmaram ter recebido explicação sobre essa prática.

As categorias que emergiram das repostas das entrevistadas estiveram relacionadas aos sentimentos expressos durante o primeiro banho do neonato no alojamento conjunto, sendo elas: "Sentimento de felicidade" e "Sentimento de medo". 
A emoção da felicidade durante a realização do banho no recém-nascido, faz com que a mãe transmita segurança e amor para o bebê, permitindo cuidar da higienização, identificar alteração e conversar, facilitando o exercício da maternidade e aumentando o vínculo.

O sentimento de alegria que envolve a mãe quando cuida do recém-nascido, se relaciona com os modos subjetivos de experimentar novas experiências, como: cuidar da sua criança, realizar o banho, trocar as fraldas e roupas, amamentar entre outros. A alegria é marcada por um estado de humor que muda a forma de lidar com as coisas e pessoas, contagiando-as. ${ }^{12}$ É importante que a mãe inicie o cuidar do seu filho, durante a hospitalização, para que possa aprender algo que venha minimizar as dificuldades de cuidado no ambiente domiciliar. ${ }^{13}$

Já o sentimento de medo, estava relacionado ao desconhecimento da melhor forma de segurar o recém-nascido no momento do banho. Relaciona-se também com a estrutura física do ambiente, onde as puérperas não conseguem ter um bom apoio para realizar esse banho dentro de uma pia, com o bebê suspenso nos braços delas.

\section{DISCUSSÃO}

Durante o banho do recém-nascido percebeu-se através das falas das mães que emergiam alguns sentimentos no primeiro contato com os mesmos. Assim, as categorias serão descritas abaixo evidenciando a felicidade e o medo demonstrado pelas mães.

\section{Sentimento de Felicidade}

O momento do banho do recém-nascido no alojamento conjunto realizado pelas genitoras é responsável por momentos de alegria e felicidade, desejo constante de ter o filho em seus braços, sendo esse um ato de carinho, amor, como foi descrito nas falas seguintes:

"[...] É muito bom, quem é que não acha bom dar banho em menino novo, muita felicidade, sem muita experiência, com medo de derrubar o menino, mais é muito prazer". (P.03)
"[...] Ah,... sinto muita alegria, felicidade, amor, é meu primeiro filho, estou muito feliz por realizar o sonho de ser mãe [...] um olhar lindo, muito bom na hora do banho, ele olha pra gente sem saber de nada, mais pra mim é tudo". (P. 15)

"[...] me sinto muito feliz em poder dá o banho no meu bebê [...] a pessoa fica animada e muito feliz, não é? brinco com meu bebê na hora do banho, eu acho graça, vontade de apertar muito, beijar, cheirar [...] alegre em dá o banho do meu bebê, cuidar da higiene dele. Fico com pena dele na hora do banho porque chora, mais é muita alegria na minha vida". (P.12)

O alojamento conjunto torna-se um ambiente propício para a aprendizagem da puérpera em relação ao banho do recém-nascido, visto que muitas apresentam medo e insegurança frente a esse cuidado e ao mesmo tempo sentimento de felicidade. A manipulação do neonato no momento do banho pode produzir diversas reações, tendo em vista que propicia uma série de trocas e ajustes interacionais entre a mãe e a criança e, portanto, potencialmente reveladora das características da reação da criança no momento da higiene. ${ }^{2}$

A finalidade do banho não só diminuir a colonização microbiana da pele e por questões estéticas e culturais da família. Este proporciona estimulação tátil e da circulação geral da pele, podendo gerar conforto, relaxamento e bem-estar, favorece uma interação harmoniosa com os pais e auxilia na adaptação do neonato à vida extrauterina. ${ }^{14}$

O banho na criança tem sido descrito como algo prazeroso, pois lembra o ambiente líquido e quente característico do útero materno. O sentimento de felicidade descrito pelas puérperas foi permeado por um sentimento único. Na maioria das vezes, sendo relacionado à emoção de dar banho em seu filho, evidenciando a importância do contato com o neonato. Como também facilita a ligação afetiva e o contato entre a díade, proporcionando bem-estar. ${ }^{2-14}$

A alegria das genitoras observada durante as falas é perceptível por meio do carinho, cuidado 
e emoções descritas pelas mesmas no momento do banho, ficando atentas a cada detalhe minucioso do banho em seu filho. Como se pode perceber nos seguintes trechos de depoimentos relatados por elas:

"[...] me emocionei bastante porque nunca tinha dado um banho em um recém-nascido, é muita felicidade. É um amor, tão grande que nem sei expressar, é tudo de bom pegar nele no banho, ver tudo bem formadinho [...] aproveito para olhar se está tudo bem com meu bebê, vejo a pele e cada parte do Corpo". (P. 22)

"[...] Ah, alegria e felicidade de tá dando o banho nele, (risada), acho que sei não dá o banho direito, aí vou dando como sei e tá dando certo, só sabendo que é meu, é muita alegria, é meu e estou pertinho dele, tocando nele, transmitindo segurança, o meu amor, olhando tudo" (P.15)

"[...] Sentimento bom de dar banho nele, alegria, amor, carinho, fico muito satisfeita, nem acredito que é meu, e quero fazer tudo, dá banho, colocar a roupa, fico conversando com ele e cantando músicas". (P. 11)

A atenção humanizada durante o cuidado neonatal deve ser o caminho norteador para que as práticas no cotidiano do cuidado sejam desenvolvidas, sendo primordial conciliar a segurança técnica dos profissionais, o respeito às características e às individualidades do recém-nascido, da mãe e da família, as condições hospitalares adequadas, a sensibilidade e o respeito ao ser que se cuida.

Nesta perspectiva, os profissionais de saúde ao cuidarem da mãe e do neonato, devem apoiar e facilitar o cuidado materno, respeitar a singularidade de cada mãe-filho, atentar ao que é dito, e flexibilizar suas rotinas instituídas. ${ }^{15}$

\section{Sentimento de Medo}

O sentimento de medo também foi expresso pelas puérperas, pois o ato de banhar o recém-nascido torna-se o primeiro cuidado real prestado pelas mães. No entanto, o receio de errar e o medo de acontecer algo desagradável podem ser minimizados no espaço do alojamento conjunto, onde as mães são orientadas para os primeiros cuidados dos seus filhos. ${ }^{16}$

No alojamento conjunto, as mães recebem orientações sobre os cuidados e também observam atentamente as atividades executadas pela equipe de enfermagem, como a realização do primeiro banho do recém-nascido. Entretanto, a observação sem a prática não é eficiente, repassar informações é diferente de ensinar, deve-se avaliar se o que foi orientado foi bem compreendido pelo aprendiz, ou se não foi interpretado de forma incorreta, de forma a prejudicar a saúde da criança. ${ }^{16,17}$

Sabe-se que a cultura representa uma influência importante no comportamento das mães, e a as crenças sobre o cuidado da puérpera têm relevância em seu cotidiano e, muitas vezes, sobrepondo às orientações recebidas na instituição de saúde. Todavia, os cuidados são compartilhados com alguém de sua confiança (geralmente a mãe, avó ou vizinha), que frequentemente possuem cultura e experiências que devem ser respeitadas e aproveitadas. ${ }^{18,19}$

Por meio das falas das depoentes, percebeu-se o sentimento de medo na execução do banho, pode ser atribuído ao tamanho do recém-nascido, onde a fragilidade é relatada pelas mães:

"[...] foi meu primeiro banho, sem prática alguma [...] eu tive muito medo do meu filho cair, escorregar, quebrar alguma coisa, porque é pequenininho, frágil, não é como nós, mais é só medo, porque é novinho demais!". (P.06)

"[...] senti muito medo no primeiro banho, não tinha prática [...] ele é tão pequeno, molinho, pequeno, eu tenho medo de pegar e ele cair, bater a cabeça [...] a moleira é muito mole, pode até furar".(P.25)

"[...] medo de escorregar, derrubar, entrar água na orelha, não sei pegar direito para dá banho e aí não dá certo, é perigoso [...] se não segurar direitinho ele cai [..] eu não tenho prática ainda [...] são essas coisas que a gente sente na hora do primeiro banho". (P.07)

Algumas participantes do estudo referiram que tinham medo de realizar o banho no 
recém-nascido, muitas vezes, por não deter a prática do banho. Além disso, demonstram a possibilidade de provocar algum acidente com o bebê, devido sua inexperiência. Com isso, evitavam realizar esse procedimento e passavam a responsabilidade para algum profissional de saúde ou acompanhante. Como foi exposto nas falas:
"[...] Tenho medo, sei lá, de não dar banho direito, tinha uma pessoa lá, eu pedi pra terminar o restante, não sei dá banho direito, dá medo, é melhor o povo daqui dá banho"(P.18)

"[...] Medo de acontecer algo, acidente, queda, bater a cabeça, não temos a técnica de dar o banho, acho que aqui é pra eles darem, na nossa casa é melhor, tem mais gente para ajudar".(P.09)

As dificuldades no manuseio do bebê durante o banho acontecem devido a fragilidade do neonato e de como segurá-lo da forma correta. Esta insegurança é compreensível, pois o cuidado especial deve ser adotado a cada movimento um recém-nascido, que deve ser manipulado com delicadeza e confiança. Corroborando com esta afirmativa, estudos demonstraram sobre a importância de ensinar sobre os cuidados antes da alta hospitalar, para que as mães possam superar as dificuldades encontradas no cuidado diário ao recém-nascido. ${ }^{20-4-14}$

O medo de manusear o recém-nascido na hora do banho também foi relatado pelas puérperas no estudo, devido às proporções pequenas daquele corpo frágil, o que torna difícil para a mãe este primeiro contato com seu filho, como podem ser percebidos nos relatos:

"[...] senti medo e estava muito ansiosa para dar o primeiro banho [...] ele é muito novinho pra gente dar banho, é muito pequeno, escorrega, é perigoso, muito medo". (P.13) "[...] fiquei com medo porque ele é pequenininho, estava muito insegura, meu bebê podia cair, mas foi só no começo, depois fica fácil". (P.14)

Sentimentos de ansiedade, medo e insegurança são comuns nas falas das puérperas durante e após o banho do recém-nascido. A nova vivência exige da mãe um lento e gradual processo de incorporação à nova condição. Para criar e compreender o bebê, a mãe se vê forçada a rever o seu papel de mulher, incorporando uma nova identificação, o de ser mãe e cuidadora, o que pode gerar conflitos internos para desempenhar o novo papel dentro da família e da sociedade. ${ }^{17-21}$

Observou-se também que o sentimento do medo estava atrelado a falta de estrutura do setor para a realização do banho, pois o local onde este era realizado proporcionava as puérperas os sentimentos de insegurança e medo na hora de sua realização. Como relatado nas frases abaixo:

"[...] susto! tive medo de queimar o menino [...] a água estava muito quente [...] o local de dar o banho no bebê é muito apertado [...] vi a hora ele cair dentro da pia [...] a estrutura aqui é muito ruim". (P.23)

"[...] a pia era muito apertada [...] eu tive medo [...] falta estrutura, não tinha como apoiar o bebê [...] tinha que ser rápido porque tinha as outras mães também para fazer o banho de seus filhos [...] só tinha uma pia e a água era muito quente". (P.04)

"[...] Eu morria de medo de dar queda [...] a pia era apertada e antiga [...] morria de medo de entrar água na orelhinha dele, de derrubar e queimar com a água quente [...] não tinha como apoiar direitinho o bebê" (P.20)

Através das falas, percebeu-se que a local onde o banho é realizado consiste num ambiente com dimensões pequenas, que abrange técnicas e cuidados que vão além da realização da higiene corporal. Outrossim, o local é utilizado para outras atividades como vacinas e vitamina $\mathrm{K}$, bem como as medidas antropométricas do RN. O local não possui privacidade, o que torna o ambiente tumultuado, além da inadequadação do chuveiro elétrico e da temperatura. A prática do banho é realizada numa pia, onde a puérpera segura a criança com receio devido risco de queda.

Este momento de higiene corporal do recém-nascido deve ser um procedimento prazeroso para quem o executa e para o bebe, permeado de contato pele a pele entre a díade 
e proporcionar estimulações táteis. Ademais, este momento deve promover a limpeza e higiene, e avaliação clínica do bebê, sendo este um desafio a ser enfrentado pelas mães e acompanhantes. ${ }^{22,23}$

A participação dos familiares no cuidado ao recém-nascido é facilitador do desenvolvimento do vínculo afetivo entre pais e filhos. Os profissionais, por vezes, não reconhecem o saber das mães em relação ao filho e apenas delegam tarefas para que elas executem ao invés de incluí-las na tomada de decisões. A inclusão da mãe no cuidado depende do interesse dos profissionais em incorporá-las. ${ }^{23-13}$

De um modo geral os depoimentos demonstram a importância de um atendimento qualidade à mãe e ao recém-nascido, para que as práticas dos cuidados diários sejam não depende exclusivamente da competência profissional individual, mas recaem sobre a organização da estrutura hospitalar e a integração da equipe. Deve-se objetivar a harmonia entre as necessidades emocionais da mãe e de sua família com as necessidades organizacionais e técnicas da instituição hospitalar. ${ }^{23}$

\section{CONCLUSÃO}

Os resultados evidenciaram que os primeiros cuidados dispensados aos recém-nascidos pelas puérperas, por meio do banho de aspersão permearam sentimentos antagônicos de felicidade e medo. A ligação entre o binômio é demonstrada por meio da alegria de estar cuidando do seu bebê durante o banho diário, bem como pelo receio de ter em mãos um ser ainda pequenino e frágil dotado de cuidados especiais.

Ademais, ao conhecer os sentimentos vivenciados pelas puérperas na realização durante este cuidado a seus filhos, suscita a importância do acompanhamento destas no alojamento conjuntos no período em que ambos se encontram internados. Nesta perspectiva, a assistência ao recém-nascido é realizada de forma humanizada, com o conhecimento ativo da puérpera sobre os primeiros cuidados dispensáveis ao recém-nascido adquirindo conotação positiva.

\section{REFERÊNCIAS}

1. Santos, SV, Costa R. Cuidados com a pele do recém-nascido: o estado da arte. J. res.: fundam. care. Online. [internet] 2015 [acesso em agosto, 2015] 7(3):2887-2901. Disponível em: http://www.seer.unirio.br/index.php/cuidadofundamental/ article/view/3814/pdf_1642http://www.seer.unirio.br/index.php/cuidadofundamental/article/view/3814/pdf_1643

2. Ministério da Saúde (Brasil). Atenção a saúde do recém-nascido. Guia para os profissionais de Saúde. Brasília: $2012 ; 2^{a}$ edição, v.1, p. 83. [Internet]. [ acesso em 15 de janeiro de 2014]. Disponível em: http://bvsms.saude.gov.br/bvs/publicacoes/ atencao_saude_recem_nascido_profissionais_v3.pdf.

3. Perini C, Seixas MC, Catão ACSM, Silva GD, Almeida VS, Matos PBCl. Ofuro bath in newborns in the rooming-in center: An experience report. J. res. fundam. care. [ internet]. 2014 abr./jun [accessed April 2014]; 6(2): 785-92. Available em: http://www.seer.unirio.br/index.php/cuidadofundamental/article/download/2851/3224.

4. Andrade LCO, Santos, MS, Aires, JS, Joventino, ES, Dodt, RCM, Ximenes, LB. Conhecimento de puérperas internadas em um alojamento conjunto acerca da higiene do neonato. Cogitare enferm. [internet]. 2012 [ acesso em março, 2013]; 17(1): 99-105. Disponível em: http://ojs.c3sl.ufpr.br/ojs/index.php/cogitare/article/viewFile/26381/17574

5. Reina R, Ferrer RX, Toro Y, Cárdenas MH. Neonatal Care Approach: a transcultural focus. Enfermería Global. [ internet]. 2010 octubre [acceso em abril 2013]; n. 20: 1-5 Disponível em: http://scielo.isciii.es/scielo.php?pid=S16956141201000 0300019\&script=sci_abstract\&tlng=em

6. Costa NS, Pereira, BDM, Machado, MOF, Mattos, JGS, Elias, TC, Silva, SR. Cuidados com recém-nascido realizados por puérperas em um alojamento conjunto. Cienc Cuid Saude. [internet] 2013 Out/Dez [acesso em 19 janeiro 2013]; 12(4):633-39. Disponível em: http://periodicos.uem.br/ojs/index.php/CiencCuidSaude/article/view/15740

7. Dantas ALB, Rocha SS, Coêlho IM, Araújo RA. Vivência de mães adolescentes após o nascimento do filho. R. Interd. [ internet] 2013 [ acesso em março 2014], 6(3): 195-203. Disponível em: http://revistainterdisciplinar.uninovafapi.edu.br/ index.php/revinter/article/view/12/pdf_55

8. Hemkemeier J, Fermino VC, Ribeiro IM. Percepção de familiares referente ao banho humanizado: técnica japonesa em recém-nascidos. Revista Ciência \& Saúde. [ internet] 2012 jan./jun [acesso em março 2014], 5 (1): 2-8. Disponível em: http://revistaseletronicas.pucrs.br/ojs/index.php/faenfi/article/view/9135 
9. Fontanella BJB, Luchesi BM, Saidel, MGB, Ricas J, Turato ER, Melo DG. Amostragem em pesquisas qualitativas: proposta de procedimentos para constatar saturação teórica. Cad. Saúde Pública, 2011 fev, Rio de Janeiro, 27(2): 389-94. Disponível em: http://www.scielosp.org/pdf/csp/v27n2/20.pdf

10. Bardin L. Análise de conteúdo. São Paulo: Edições 70; 2011.

11. Brasil. Ministério da saúde. Conselho Nacional de Saúde. Resolução 466 de 23 de dezembro de 2013. Aprova as diretrizes e normas regulamentadoras de pesquisa envolvendo seres humanos. Brasília (DF); 466. Disponível em: http:// bvsms.saude.gov.br/bvs/saudelegis/cns/466/res466_23_12_2013.html

12. Duarte ED, Sena RR, Tavares TS. Práticas cuidadoras que favorecem a integralidade do cuidado ao recém-nascido de alto risco: revisão sistemática. Rev. Eletrônica de Enfermagem. 2010; 12(3): 539-46.

13. Perini C, Seixas MC, Catão ACSM, Silva GD, Almeida VS, Matos PBC. Banho de ofurô em recém-nascidos no alojamento conjunto: um relato de experiência. J. res.: fundam. Care online [internet]. 2014. [acesso em agosto, 2015]; 6(2):785-92. Disponível em: http://www.seer.unirio.br/index.php/cuidadofundamental/article/view/2851/pdf_1284http://www.seer.unirio. br/index.php/cuidadofundamental/article/view/2851/pdf_1285

14. Richetto AM, Souza ABG. A Higiene do recém-nascido e cuidados com o coto umbilical. In: SOUZA ABG, et al. Enfermagem neonatal: cuidado integral ao recém-nascido. 2011, São Paulo: Martinari, p. 107- 13.

15. Spehar MC, Seid EMF. Percepções maternas no método canguru: contato pele a pele, amamentação e autoeficácia. Psicologia em Estudo, Maringá. [internet]. 2013 [ acesso em agosto, 2015]; 18(4):. 647-56. Disponível em: http://www. scielo.br/pdf/pe/v18n4/07.pdf

16. Müller EB, Zampieri MFM. Prática educativa com enfermeiras visando o cuidado humanizado ao recém-nascido no centro obstétrico. Texto Contexto Enferm [internet]. 2014 [ acesso em agosto, 2015]; 23(3): 782-90. Disponível em: http:// www.scielo.br/pdf/tce/v23n3/pt_0104-0707-tce-23-03-00782.pdf

17. Souza Carvalhêdo D, Monteiro LF., Rodrigues SBMA, Gaíva M, \& LISBOA SR. As vivências e os significados do primeiro banho dado pela puérpera em seu filho recém-nascido. Enfermería Global, 2010, n.1(19): p. 1-15.

18. Costa NS, Soares MBO, Melo MM, Parreira BDM, Silva SR. Prática do autocuidado e demandas por cuidados de enfermagem pelas puérperas. REAS [Internet]. 2013 [ acesso em agosto, 2015]; 2(1):75-8. Disponível em: http://reitoria.uftm. edu.br/revistaeletronica/index.php/enfer/article/view/378/394

19. Nascimento L, et AL. Entendimento dos(as) enfermeiros(as) sobre a comunicação dos recém-nascidos. Revista Baiana de Enfermagem [internet]. 2012 [acesso em agosto, 2015]; 26 (3): 604-11. Disponível em: http://www.portalseer.ufba.br/ index.php/enfermagem/article/viewArticle/6363

20. Couto FF, Praça NS. Recém-nascido prematuro: suporte materno domiciliar para o cuidado. Revista Brasileira de Enfermagem. 2012 Jan-Fev; Brasília, n. 1(65), p. 19-26.

21. Pereira MC, Garcia, ESGF, Andrade, MBT, Gradim, CV. Sentimentos da puérpera primípara nos cuidados com o recém-nascido. Cogitare Enfermagem. 2012 Jul-Set; 17(3): 537-42.

22. Pugliesi VEM, Deutsch, ADA, Freitas, M, Dornaus, MFPS, Rebello, CM. Efeitos do banho logo após o nascimento sobre as adaptações térmica e cardiorrespiratória do recém-nascido a termo. Rev. paul. Pediatr. [ internet]. 2010 [acesso em maio de 2014]; 27(4):410-15. Disponível em: http://www.scielo.br/scielo.php?script=sci_arttext\&pid=S0103-05822009000400010 23. Guerreiro EM, Rodrigues DP, Queiroz ABA, Ferreira MA. Educação em saúde no ciclo gravídico-puerperal: sentidos atribuídos por puérperas. Rev Bras Enferm. [Internet]. 2014 [acesso em agosto de 2015]; 67(1): 13-21. Disponível em: http://www.scielo.br/pdf/reben/v67n1/0034-7167-reben-67-01-0

Recebido em: 16 de julho de 2014. Aprovado em: 13 de setembro de 2015. 